\title{
Selective Deletion of Sodium Salt Taste during Development Leads to Expanded Terminal Fields of Gustatory Nerves in the Adult Mouse Nucleus of the Solitary Tract
}

\author{
Chengsan Sun, ${ }^{1}$ Edith Hummler, ${ }^{2}$ and David L. Hill ${ }^{1}$ \\ ${ }^{1}$ Department of Psychology, University of Virginia, Charlottesville, Virginia 22904-4400, and 2Pharmacology and Toxicology Department, Faculty of Biology \\ and Medicine, University of Lausanne, CH-1005 Lausanne, Switzerland
}

\begin{abstract}
Neuronal activity plays a key role in the development of sensory circuits in the mammalian brain. In the gustatory system, experimental manipulations now exist, through genetic manipulations of specific taste transduction processes, to examine how specific taste qualities (i.e., basic tastes) impact the functional and structural development of gustatory circuits. Here, we used a mouse knock-out model in which the transduction component used to discriminate sodium salts from other taste stimuli was deleted in taste bud cells throughout development. We used this model to test the hypothesis that the lack of activity elicited by sodium salt taste impacts the terminal field organization of nerves that carry taste information from taste buds to the nucleus of the solitary tract (NST) in the medulla. The glossopharyngeal, chorda tympani, and greater superficial petrosal nerves were labeled to examine their terminal fields in adult control mice and in adult mice in which the $\alpha$-subunit of the epithelial sodium channel was conditionally deleted in taste buds ( $\alpha \mathrm{ENaCknockout).}$ The terminal fields of all three nerves in the NST were up to 2.7 times greater in $\alpha \mathrm{ENaC} \mathrm{knock-out} \mathrm{mice} \mathrm{compared} \mathrm{with} \mathrm{the} \mathrm{respective} \mathrm{field}$ volumes in control mice. The shapes of the fields were similar between the two groups; however, the density and spread of labels were greater in $\alpha \mathrm{ENaC}$ knock-out mice. Overall, our results show that disruption of the afferent taste signal to sodium salts disrupts the normal age-dependent "pruning" of all terminal fields, which could lead to alterations in sensory coding and taste-related behaviors.
\end{abstract}

Key words: activity; axons; ENaC; epithelial sodium channel; knock out; medulla

Significance Statement

Neural activity plays a major role in the development of sensory circuits in the mammalian brain. To date, there has been no direct test of whether taste-elicited neural activity has a role in shaping central gustatory circuits. However, recently developed genetic tools now allow an assessment of how specific taste stimuli, in this case sodium salt taste, play a role in the maturation of the terminal fields in the mouse brainstem. We found that the specific deletion of sodium salt taste during development produced terminal fields in adults that were dramatically larger than in control mice, demonstrating for the first time that sodium salt taste-elicited activity is necessary for the normal maturation of gustatory inputs into the brain.

\section{Introduction}

The role of experience on the development of central sensory circuits has been of keen interest in neuroscience since the early work by Hubel and Wiesel (1962)). While most studies on this

Received Sept. 16, 2016; revised Nov. 4, 2016; accepted Dec. 1, 2016.

Author contributions: C.S., E.H., and D.L.H. designed research; C.S. and D.L.H. performed research; C.S. and D.L.H. analyzed data; C.S., E.H., and D.L.H. wrote the paper.

This work was supported by National Institutes of Health Grant DC-00407 (to D.L.H.) and by Swiss National Science Foundation Grant 31003A_163347/1 (to E.H.). We thank Dr. Shuqiu Zheng and Maureen Cowan for their excellent technical assistance.

The authors declare no competing financial interests.

Correspondence should be addressed to Dr. David L. Hill, Department of Psychology, PO Box 400400, University of Virginia, Charlottesville, VA 22904. E-mail: dh2t@virginia.edu.

DOI:10.1523/JNEUROSCI.2913-16.2016

Copyright $\odot 2017$ the authors $\quad 0270-6474 / 17 / 370660-13 \$ 15.00 / 0$ topic center on cortical development, work focused on lower neural level circuits show some, but usually lower levels of, dependence on neural activity. For example, in the retinogeniculate pathway, terminal fields of retinal ganglion cells in the dorsal lateral geniculate nucleus (dLGN) are shaped by intrinsic waves of activity in the retina before the eyes open (Katz and Shatz, 1996; Hooks and Chen, 2006). These circuits are ultimately refined through competitive, activity-dependent mechanisms at about the time, and extending after, the eyes open (Chen and Regehr, 2000; Hooks and Chen, 2006; Ziburkus and Guido, 2006). Thus, both spontaneous and visually evoked stimuli help orchestrate the organization of visual inputs into the dLGN.

By comparison, little is known about the subcortical development of the gustatory system, circuits that are intimately involved in driving feeding and motivated behaviors (Spector and Travers, 
2005; Spector and Glendinning, 2009). We do know, however, that some of the anatomical hallmarks that are characteristic of other developing sensory neural structures occur in the developing gustatory system (Mistretta and Hill, 2003; Mangold and Hill, 2008). Cranial nerves that innervate taste buds in the rodent tongue and palate initially have relatively large and overlapping terminal fields in the nucleus of the solitary tract (NST) in the medulla (Mangold and Hill, 2008). These profuse projections then decrease dramatically in size at around the time of weaning (Sollars et al., 2006; Mangold and Hill, 2008), which is about the age when taste-elicited activity (especially to $\mathrm{NaCl}$ ) increases more than twofold in magnitude. While there is converging evidence that taste-elicited neural activity plays a role in this postnatal refinement of terminal fields (Hill and Bour, 1985; Vogt and Hill, 1993; Mangold and Hill, 2008; Corson and Hill, 2011), no direct test of this hypothesis has been available.

Recently, however, the ability to selectively alter taste experience to a specific stimulus has been provided by Chandrashekar et al. (2010). They showed that the transduction channel for sodium taste could be deleted from mouse taste bud cells throughout development. Moreover, they found that adult mice lacking the functional sodium salt taste transducer throughout life had a selective suppression of salt taste responses from the chorda tympani (CT) nerve, which innervates taste buds on the anterior tongue. They also demonstrated that mice lacking the functional transducer for salt taste lacked the appropriate behavioral responses driven by $\mathrm{NaCl}$ (Chandrashekar et al., 2010). This knockout mouse is an ideal experimental model to ask questions related to the role of taste elicited activity on the development and plasticity of central gustatory circuits for multiple reasons. Taste nerve responses to $\mathrm{NaCl}$ begin in rodents at approximately postnatal day 11 (P11; Hill and Bour, 1985) and then appear to change the most compared to responses to all other stimuli to adulthood (Hill and Almli, 1980; Yamada, 1980; Ferrell et al., 1981), and because sodium taste plays such an important role in homeostasis and motivated behaviors (Denton, 1982; Schulkin, 1991). We show here that, indeed, lack of sodium taste throughout development has profound effects on how nerves that carry taste information project to their central targets. Unexpectedly, the terminal fields of all nerves, even of one that does not carry sodium salt taste information, are permanently affected by this genetic deletion. Our results suggest that there is a lack of maturation of the terminal fields due to the loss of sodium salt taste activity. This is the first clear demonstration that alteration of a single taste modality is critical for the normal development of taste-related circuits.

\section{Materials and Methods Animals}

All experiments were approved by the University of Virginia Animal Care and Use Committee and followed guidelines set forth by the National Institutes of Health and the Society for Neuroscience. To examine the role of lack of sodium salt taste on the development of terminal field organization in the rostral NST, we used mice described in detail by Chandrashekar et al. (2010). Briefly, the $\alpha$-subunit of the epithelial sodium channel $(\alpha \mathrm{ENaC})$ was conditionally deleted in taste bud cells by crossing mice that drove the expression of Cre-recombinase under the cytokeratin 19 (CreK19) promotor (Chandrashekar et al., 2010) with mice that were a homozygous mutant for the floxed Scnn1a $(\alpha \mathrm{ENaC})$ gene (Scnn1a flox/flox; Hummler et al., 2002). The CreK19 mice were generously supplied by Dr. Charles Zuker, Columbia University, and Dr. Edith Hummler, University of Lausanne, Switzerland, supplied the Scnn 1a flox/flox mice. Therefore, our experimental animals had the genotype K19-Cre Scnnla flox/flox $(\alpha \mathrm{ENaC}$ knockout; $n=6)$. The control group consisted of mice that were littermates to experimental animals, but did not have the CreK19 promoter $\left(S c n n 1 a^{\text {flox/flox }} ; n=4\right)$ or lacked K19-Cre and Scnn1 $a^{\text {flox/flox }}(n=3)$. We subsequently found no differences in any of our measures for these two groups of control mice; thus, we pooled data from all seven mice (controls). All animals were between 60 and $120 \mathrm{~d}$ old at the time of the experiments, and both male and female mice were used.

Tissue collection. To establish that the mice used here had Scnn1a removed in the tongue, we used quantitative real-time PCR (qRT-PCR) procedures similar to those of Huang and Krimm (2010) and Sun et al. (2015).

Briefly, the anterior two-thirds of fresh tongues from $\alpha \mathrm{ENaC}$ knockout mice $(n=4)$ and control mice $(n=4)$ were collected and cut at the midline, rinsed with cold PBS, and then incubated in sterile dispase I solution (BD Biosciences) for $60 \mathrm{~min}$ at $37^{\circ} \mathrm{C}$. Epithelial sheets of the tongue were then peeled from the underlying mesenchyme and immediately processed for RNA extraction.

RNA extraction and $q R T-P C R$. Total RNA was extracted using RNeasy Mini-Kit (Qiagen). Traces of DNA were eliminated in samples by treatment with DNase I. Total RNA was analyzed as described in detail by Sun et al. (2015). Reverse transcription was performed using 200 U of Superscript III Reverse Transcriptase (ThermoFisher Scientific) and $50 \mathrm{ng}$ of random hexamers in $25 \mathrm{ml}$ reaction volumes following the manufacturer protocol with the same amount (50 ng) of total RNA. qRT-PCR was performed by the 7500 Fast Real-Time PCR System (ThermoFisher Scientific) using the Taq-Man Universal PCR Kit. Assays of $\alpha \mathrm{ENaC}$ and glyceraldehyde-3-phosphate dehydrogenase (GAPDH; Mm00803386_m1 and Mm99999915_g1, respectively; catalog \#4331182) were purchased from ThermoFisher Scientific. PCR efficiencies were determined by performing PCR with serial (10-fold) dilutions of cDNA in parallel. All samples were run in parallel with the housekeeping gene mouse GAPDH to normalize cDNA loading. Each assay was performed in triplicate. PCR was performed for 40 cycles at $95^{\circ} \mathrm{C}$ for $15 \mathrm{~s}$ and at $60^{\circ} \mathrm{C}$ for $1 \mathrm{~min}$.

$q R T-P C R$ analyses. For qRT-PCR, the comparative $2^{-\Delta \Delta C T}$ method was used to determine the relative Scnnla gene expression levels (Huang and Krimm, 2010; Sun et al., 2015).

Fluorescent anterograde nerve labeling. Procedures used to label three nerves with fluorescent tracers were the same as those described previously in the mouse (Sun et al., 2015). Briefly, the CT, greater superficial petrosal (GSP), and the glossopharyngeal (IX) nerves were labeled with anterograde tracers to determine the volume and densities of labeling among gustatory afferent terminal fields in the NST. The CT nerve carries taste information from taste buds in fungiform papillae on the anterior tongue and in the anterior foliate papillae on the posterior tongue to the NST. The GSP nerve carries taste information from taste buds on the soft palate, the geschmacksstreifen, and the nasoincisor duct in the palate to the NST. The IX nerve carries taste information from taste buds in the circumvallate papilla and the posterior foliate papillae, both on the posterior tongue, to the NST (for a diagram of innervation patterns, see Sun et al., 2015).

All animals were between 3 and 4 months old at the time of nerve labeling, which are ages beyond the age when mature-like terminal field organization occurs (Mangold and Hill, 2008). Mice were sedated with a $0.32 \mathrm{mg} / \mathrm{kg}$, i.m., injection of medetomidine hydrochloride (Domitor, Pfizer Animal Health) and anesthetized with $40 \mathrm{mg} / \mathrm{kg}$, i.m., ketamine hydrochloride (Ketaset, Fort Dodge Animal Health). A water-circulating heating pad was used to maintain body temperature. Mice were positioned in a nontraumatic head holder (Erickson, 1966), and a ventral approach was taken to expose the GSP and CT nerves within the right tympanic bulla. The CT and GSP nerves were cut near and peripheral to the geniculate ganglion in the tympanic bulla; crystals of $3 \mathrm{kDa}$ tetramethylrhodamine dextran amine were applied to the proximal cut end of the GSP nerve, and crystals of $3 \mathrm{kDa}$ biotinylated dextran amine were applied to the proximal cut end of the CT nerve. The IX nerve was isolated medial to the tympanic bulla, which was cut peripheral to the petrosal ganglion, and placed on a small piece of Parafilm. Crystals of 3 $\mathrm{kDa}$ cascade blue dextran amine were applied to the proximal cut end of the IX nerve. A small amount of Kwik-Sil (World Precision Instruments) was then placed over the cut end of the nerves to prevent crystals from 
diffusing from the site of the intended label. All dextran amine conjugates were purchased from ThermoFisher Scientific. Animals were then injected with $5 \mathrm{mg} / \mathrm{ml}$, i.m., atipamezole hydrochloride (Antisedan, Pfizer Animal Health) to promote reversal of anesthesia. Following $48 \mathrm{~h}$ of survival, animals were deeply anesthetized with urethane and transcardially perfused with Krebs-Henseleit buffer, $\mathrm{pH} 7.3$, followed by $4 \%$ paraformaldehyde, $\mathrm{pH}$ 7.2.

Tissue preparation. Brains were removed and postfixed, and the medulla was blocked and sectioned horizontally on a vibratome at $50 \mu \mathrm{m}$ (Sun et al., 2015). We chose to section tissue in the horizontal plane because it allows visualization of the entire rostral-caudal and medial lateral extent of the terminal fields in the NST with the smallest number of sections ( $\sim 10$ sections/mouse). It is also the plane in which the axons branch from the solitary tract and primarily project medially in rodents (Davis, 1988; Whitehead, 1988; Lasiter et al., 1989).

Sections were then incubated for $1 \mathrm{~h}$ in PBS containing $0.2 \%$ Triton with 1:400 streptavidin Alexa Fluor 647 (Jackson ImmunoResearch) and 1:400 rabbit anti-Cascade Blue (ThermoFisher Scientific) at room temperature. Streptavidin Alexa Fluor 647 was used to visualize the biotinylated dextran amine-labeled CT-positive terminals. Rabbit anti-Cascade Blue was used as a primary antibody to detect Cascade Blue-labeled IX terminal fields and was followed with a $1 \mathrm{~h}$ reaction with 1:400 donkey anti-rabbit Alexa Fluor 488 (Jackson ImmunoResearch). This secondary antibody was used to visualize IX nerve terminals. Visualization of tetramethylrhodamine, which labeled GSP terminal fields, did not require further processing. Sections were mounted on slides and coverslipped with Vectashield Hardset Mounting Medium (Vector Laboratories).

Confocal microscopy and analyses of terminal fields. Terminal fields were imaged using a Nikon 80i Microscope fitted with a Nikon C2 Scanning System (Nikon Instruments) and a $10 \times$ objective [numerical aperture (NA), 0.45; CFI Plan Apochromat, Nikon]. The nerve labels were matched for the wavelengths of the three lasers in the system (argon laser: $488 \mathrm{~nm}, 10 \mathrm{~mW}$, IX nerve; DPSS laser: $561 \mathrm{~nm} ; 10 \mathrm{~mW}$, GSP nerve; modulated diode laser: $638 \mathrm{~nm}, 20 \mathrm{~mW}$, CT nerve). Sequential optical sections were captured every $3 \mu \mathrm{m}$ for each $50 \mu \mathrm{m}$ section. Images were obtained with settings adjusted so that pixel intensities were near (but not at) saturation. A transmitted light image at $4 \times(\mathrm{NA}, 0.13$; Plan Fluor, Nikon) and at $10 \times$ was captured for every physical section containing the labeled terminal field. This permitted an accurate registration of dorsalto-ventral brainstem sections among animals within and between groups using common brainstem landmarks $(4 \times)$, and the identification of NST borders $(10 \times)$.

Analyses of total terminal field volume. Methods used to analyze terminal field volumes and densities were described previously in detail (Sun et al., 2015). Briefly, quantification of terminal field volume was achieved through the use of custom ImageJ-based software (Sun et al., 2015). Each image stack was initially rotated so that the solitary tract was oriented vertically. The border of the NST was outlined for each physical section through the use of the corresponding transmitted light image, and the stack was then cropped to include only the NST. The IsoData thresholding algorithm (Ridler and Calvard, 1978) was then applied to yield a binary image stack of the labeled pixels above threshold. A particle analysis was then performed to quantify the pixel area above threshold for each channel. Specifically, the number of pixels above threshold for each optical section was summed by ImageJ, converted into area by multiplying the number of pixels by pixel size $(1.24 \times 1.24 \mu \mathrm{m})$, and then multiplied by $3 \mu \mathrm{m}$ (i.e., distance between optical sections) to determine the volume of each label in each physical section. Volumes from each physical section were summed to yield the total terminal field volume for each mouse. The resultant volume represents an unbiased experimenter measure of the amount of label. Additionally, the volume of colocalization between the terminal fields of two nerves (CT with GSP, GSP with IX, CT with IX) and among all three nerves (CT, GSP, and IX) was determined in a manner similar to that described for each single label.

Axons (e.g., the solitary tract) were included along with the terminal field for all animals in our analyses because of the difficulty in accurately deleting axons and tracts from each optical section. Accordingly, the absolute volumes that we show here include the composite terminal field and axons. There was no obvious reorganization of nerve tracts among groups; therefore, we make the assumption that including the solitary tract in our measurements had a similar quantitative effect among groups.

Analyses of terminal field volume and density of labels in dorsal-ventral zones. The analyses of terminal field volumes and density here is the same as was performed to study the role of $B d n f$ overexpression in the tongue on terminal field organization in the NST (Sun et al., 2015). The NST was subdivided into $x$-, $y$-, and $z$-planes to help identify where terminal field organization of each nerve and the overlaps with other terminal fields occurred. For the medial-lateral and rostral-caudal analyses ( $x$ - and $y$-planes), the NST in the horizontal plane was subdivided into uniform grid boxes of $100 \times 100$ pixels. The grid was aligned relative to the NST, with the intersection of the most medial and most rostral borders of the NST as the 0,0 coordinate. The density of the terminal field label was calculated in each grid box $(100 \times 100$ pixels $)$ for each physical section by dividing the respective terminal field volume within a grid box by the volume of the portion of the NST contained within the grid box (i.e., the volume of terminal field label/volume of the NST within the grid box).

For analyses in the dorsal-ventral planes ( $z$-plane), we examined the volume of labeled terminal fields in four dorsal-ventral zones (for details, see Sun et al., 2015). The landmarks in controls and $\alpha \mathrm{ENaC}$ knock-out mice were similar to those described by Sun et al. (2015).

Examination of terminal fields in coronal sections. The NST from three $\alpha \mathrm{ENaC}$ knock-out mice and three control mice were sectioned coronally on a vibratome at $50 \mu \mathrm{m}$ and imaged as described above. Coronal sections were used to examine the extent of terminal field expansion and overlapping fields in the NST. No quantitative measurements were obtained. Coronal sections were also imaged with transmitted light following confocal microscopy of the fluorescently labeled terminal fields to allow the visualization of labeled chorda tympani nerve terminal fields in coronal sections.

Geniculate ganglion and petrosal ganglion cell number. The CT nerve ( $\alpha \mathrm{ENaC}$ knock-out mice, $n=4$; controls, $n=4$ ) or the GSP nerve ( $\alpha \mathrm{ENaC}$ knock-out mice, $n=4$; controls, $n=4$ ) was labeled as described for the terminal field labeling procedure, with the exception that the 3 $\mathrm{kDa}$ tetramethylrhodamine dextran was chosen as the only tracer because it did not require further processing for visualization. After cardiac perfusion, the brain was removed to gain access to ganglia. Geniculate ganglia were then removed ventrally through the base of the skull with the aid of a surgical microscope. Petrosal ganglia $(\alpha \mathrm{ENaC}$ knock-out mice, $n=4$; controls, $n=4$ ) were also labeled with the tetramethylrhodamine tracer by labeling the IX nerve. Following cardiac perfusion, petrosal ganglia were removed along with a portion of the IX nerve, using the approach described for the nerve-labeling technique. All ganglia were postfixed overnight. Each intact ganglion was mounted on a slide and imaged on a scanning laser confocal microscope. Serial $2 \mu \mathrm{m}$ optical sections were obtained throughout each ganglion, as described previously in the mouse (Shuler et al., 2004). Cell numbers were counted using Neurolucida computer software (version 4.34, MicroBrightField).

Measures of NST volumes. The transmitted light images $(4 \times)$ obtained of all sections in control mice and in $\alpha \mathrm{ENaC}$ knock-out mice were used to determine whether the size of the NST differed between groups. The NST volume was measured using Neurolucida computer software (version 4.34, MicroBrightField). To calculate volume, the area measurements from all of the sections were summed and multiplied by $50 \mu \mathrm{m}$.

Measures of NST neuron density. We asked whether group-related changes in terminal field size could be explained by differences in the density of neurons in the NST. To make this assessment, adult control mice $(n=3)$ and $\alpha \mathrm{ENaC}$ knock-out mice $(n=4)$ were overdosed, perfused, and fixed, and brains were sectioned as described in the sections Fluorescent anterograde nerve labeling and Tissue preparation. Horizontal sections were placed in NeuroTrace 530/615 red fluorescent Nissl stain (1:200; catalog \#N21482, ThermoFisher Scientific) for $30 \mathrm{~min}$, washed, and then mounted on glass slides.

For analyses, we compared the density of NST neurons between controls and $\alpha \mathrm{ENaC}$ knock-out mice by counting neurons in a common section across animals in the dorsal zone and another common section from the intermediate zone of the NST. Sections were matched across animals through the use of brainstem landmarks, as detailed by Sun et al., 
2015. Images were analyzed using Nikon Elements software (version AR4.13). A region of interest (ROI) was drawn such that the border of the NST was outlined beginning at the rostral pole and extended along the medial and lateral aspects of the NST. These medial and lateral lines were then joined by a line perpendicular to a line extending $500 \mu \mathrm{m}$ caudal from the rostral pole and bisecting the NST.

The method described to count NeuroTrace-stained cells in the mouse anterior piriform cortex was used (Suzuki and Bekkers, 2010). Briefly, a single confocal optical section located $6 \mu \mathrm{m}$ beyond a $12 \mu \mathrm{m}$ guard zone was selected, and all nuclei of Nissl-stained cells were counted within the ROI. Neurons were counted only when the nucleus was identified. The effective thickness was calculated to be $13 \mu \mathrm{m}$. The number of cells was then divided by the effective volume to derive the density of NST neurons per $100,000 \mathrm{~mm}^{3}$. Such an analysis is similar to the Abercrombie method for counting cells (Guillery, 2002).

\section{Statistical Analysis}

Terminal field volumes. The mean \pm SEM was calculated for the total CT, GSP, and IX nerve terminal field volumes, for their overlapping field volumes, and for terminal field volumes within the four defined dorsalventral zones. Comparisons were made for the volume of each nerve and the overlap between the control and $\alpha \mathrm{ENaC}$ knock-out mice using independent-samples $t$ tests. The Holm-Sidak step-down test was used to correct for multiple comparisons. We chose to start the step-down process with the unadjusted $\alpha$ level at 0.05 (Holm, 1979).

Density by dorsal-ventral zones. Density measures were not statistically analyzed but were qualitatively examined through heat maps for each dorsal-ventral zone containing a $5 \times 10$ (column $\times$ row) grid.

Ganglion cell counts. Ganglion cell numbers were compared between $\alpha \mathrm{ENaC}$ knock-out and control mice and analyzed using independentsamples $t$ tests. As noted in the statistical description for terminal field analyses, the Holm-Sidak step-down test was used to correct for multiple comparisons of ganglion cell numbers (i.e., cells of the CT, GSP, and IX nerves). We chose to start the step-down process with the unadjusted $\alpha$ level at 0.05 (Holm, 1979).

NST volumes and NST neuron counts. The mean total NST volumes and neuron cell counts in the dorsal zone and intermediate zone were each compared between the two groups using an independentsamples $t$ test.

CT nerve neurophysiology. To establish that the knockout of the Scnn1a in the tongue resulted in reduced functional responses from the CT and GSP nerves to $\mathrm{NaCl}$ at adulthood ( $\alpha \mathrm{ENaC}$ knock-out mice, $n=4$; controls, $n=5$ ) were anesthetized as described for the fluorescent anterograde nerve-labeling procedure. The animals were tracheotomized and placed on a circulating water heating pad to maintain body temperature. Hypoglossal nerves were transected bilaterally to prevent tongue movement, and the mouse was placed in a nontraumatic head holder. The left CT nerve was isolated using a mandibular approach. The nerve was exposed near the tympanic bulla, cut, desheathed, and positioned on a platinum electrode. A second electrode was placed in nearby muscle to serve as a ground. Kwik-Sil was placed in the cavity around the nerve.

Functional taste responses were also recorded from the GSP nerve in a $\alpha \mathrm{ENaC}$ knock-out mouse and a control mouse. The neurophysiological procedure was followed as detailed by Sollars and Hill $(1998,2000)$. Briefly, the heads of mice were held and stabilized by a nontraumatic headholder (Erickson, 1966) and placed in a supine position. The GSP nerve was sectioned close to the geniculate ganglion and dissected free of underlying tissue. The nerve was desheathed and positioned on a platinum electrode, with a reference electrode placed in nearby tissue.

Whole nerve CT or GSP activity was fed to a high-impedance input stage amplifier and then led to a PowerLab analog-to-digital converter and amplifier and was analyzed with PowerLab Scope software (ADInstruments). The output of the PowerLab software was fed to an audio monitor and to a computer monitor for monitoring activity.

Stimulation procedure. All chemicals were reagent grade and prepared in artificial saliva (Hellekant et al., 1985). Neural responses from the CT nerve were recorded to ascending concentrations series of $0.05,0.1,0.25$, and $0.5 \mathrm{M} \mathrm{NaCl}$, to 10,20 , and $50 \mathrm{~mm}$ citric acid, then to $0.1,0.25,0.5$, and $1.0 \mathrm{~m}$ sucrose, and finally to $10,20,50$, and $100 \mathrm{~mm}$ quinine hydrochlo- ride to assess the taste responses to prototypical stimuli that represent salty, sour, sweet, and bitter, respectively, to humans. The concentration series to taste stimuli were similar to those used by Chandrashekar et al. (2010). Each concentration series was bracketed by applications of $0.5 \mathrm{M}$ $\mathrm{NH}_{4} \mathrm{Cl}$ to monitor the stability of each preparation and for normalizing taste responses. Solutions were applied to the tongue in $5 \mathrm{ml}$ aliquots with a syringe and allowed to remain to the tongue for $\sim 20 \mathrm{~s}$. We used this period of stimulation so that we could ensure enough of a period to measure steady-state responses. After the application of each solution, the tongue was rinsed with artificial saliva for $\geq 1 \mathrm{~min}$. This period allowed a full recovery of neural responses (i.e., the responses were not adapted by previous responses; Shingai and Beidler, 1985). In addition, responses were recorded to the $\mathrm{NaCl}$ concentration series in the epithelial sodium channel blocker amiloride $(50 \mu \mathrm{M})$. Rinses during this series were to amiloride. Neural responses from the GSP nerve were recorded only to an ascending concentration series of $0.05,0.1,0.25$, and $0.5 \mathrm{M} \mathrm{NaCl}$ before and after lingual application of amiloride. For both CT and GSP nerve recordings, the stimuli were mixed in artificial saliva and the rinses were performed with amiloride dissolved in artificial saliva.

CT and GSP nerve responses were calculated as follows: the average voltage of the spontaneous activity that occurred for the second before stimulus onset was subtracted from the voltage that occurred from the period from the first to sixth second after stimulus application. Response magnitudes were then expressed as ratios relative to the mean of $0.5 \mathrm{M}$ $\mathrm{NH}_{4} \mathrm{Cl}$ responses before and after stimulation. Whole-nerve response data were retained for analysis only when $0.5 \mathrm{M} \mathrm{NH}_{4} \mathrm{Cl}$ responses that bracketed a concentration series varied by $<10 \%$.

\section{Results}

Scnn 1a expression was significantly decreased in $\alpha \mathrm{ENaC}$ knock-out mice

Expression of the Scnnla gene in the tongue of $\alpha \mathrm{ENaC}$ knock-out mice was $9 \%$ of that in controls at adulthood. The mean ( \pm SEM) normalized expression ratio for controls was $1.05 \pm 0.04$, and for $\alpha \mathrm{ENaC}$ knock-out mice, $0.09 \pm 0.02(p<0.0001)$.

\section{Neurophysiological taste responses to $\mathrm{NaCl}$ from the $\mathrm{CT}$ and GSP nerves were decreased in $\alpha \mathrm{ENaC}$ knock-out mice}

Conditionally deleting the Scnnla gene in the taste buds throughout the oral cavity had profound and selective effects on CT nerve taste responses. In $\alpha \mathrm{ENaC}$ knock-out mice, increases in the concentration of $\mathrm{NaCl}$ as the taste stimulus did not increase the taste responses in the CT nerve like that seen in control mice (Fig. $1 A-D)$. For example, the relative responses of the CT nerve to 0.1 , 0.25 , and $0.5 \mathrm{M} \mathrm{NaCl}$ in $\alpha \mathrm{ENaC}$ knock-out mice were significantly less $(40-60 \%)$ than the respective responses in control mice $(p<0.05$; Fig. $1 E)$. Moreover, the epithelial sodium channel blocker amiloride had no significant suppressive effect on $\mathrm{NaCl}$ taste responses in the CT nerve of $\alpha \mathrm{ENaC}$ knock-out mice, indicating that the response to $\mathrm{NaCl}$ in these mice was through amiloride-insensitive transduction pathways. By contrast, amiloride significantly suppressed $\mathrm{NaCl}$ responses in controls to $0.1,0.25$, and $0.5 \mathrm{M} \mathrm{NaCl}(p<0.05$; Fig. $1 E)$, resulting in response magnitudes similar to those seen in $\alpha \mathrm{ENaC}$ knock-out mice. Thus, as expected, the deletion of $\alpha \mathrm{ENaC}$ did not appear to affect non-amiloride-sensitive $\mathrm{NaCl}$ taste response. In contrast to $\mathrm{NaCl}$ taste stimulation, responses of the $\mathrm{CT}$ nerve to nonsalt stimuli were similar between $\alpha \mathrm{ENaC}$ knock-out and control mice throughout a concentration range for sucrose, citric acid, and quinine hydrochloride (Fig. 2). The type and magnitude of the changes seen here for CT nerve responses in $\alpha \mathrm{ENaC}$ knock-out mice were similar to those reported by Chandrashekar et al. (2010).

In the rat, the GSP nerve also responds robustly to taste stimulation with $\mathrm{NaCl}$, and these responses are suppressed by amiloride (Sollars and Hill, 1998, 2000). We show here that the GSP nerve in a 


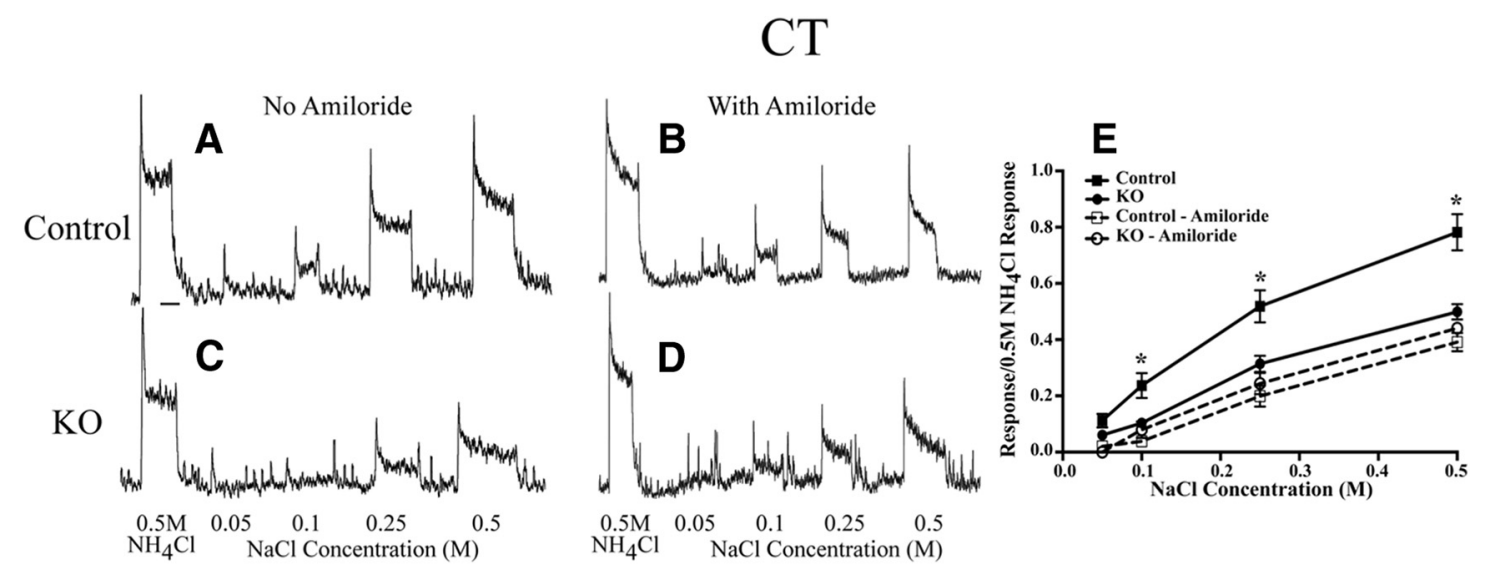

GSP
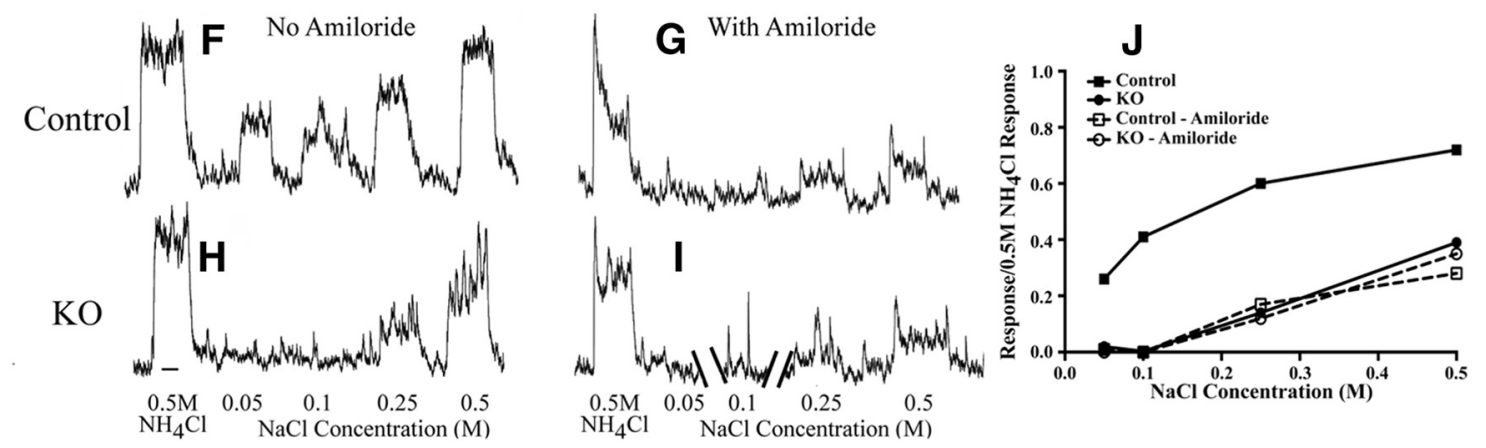

Figure 1. $\quad \boldsymbol{A}, \boldsymbol{B}$, Integrated taste responses from the $\mathrm{CT}$ nerve in a control (Control) mouse to a concentration series of $\mathrm{NaCl}$ and to $0.5 \mathrm{M} \mathrm{NH}_{4} \mathrm{Cl}$ before lingual application of the epithelial channel blocker amiloride $(\boldsymbol{A})$ and with amiloride $(\boldsymbol{B})$. $\boldsymbol{C}, \boldsymbol{D}$, Integrated taste responses from the $\mathrm{CT}$ in an $\alpha \mathrm{ENaC}$ knock-out (K0) mouse to a concentration series of $\mathrm{NaCl}$ and to $0.5 \mathrm{M} \mathrm{NH} \mathrm{Cl}_{4} \mathrm{Cl}$ before lingual application of amiloride $(\boldsymbol{C})$ and with amiloride $(\boldsymbol{D})$. $\boldsymbol{E}$, Mean ( \pm SEM) relative taste responses to a concentration series of $\mathrm{NaCl}$ from the $\mathrm{CT}$ in control and $\alpha \mathrm{ENaC} \mathrm{KO}$ mice before (solid lines) and with lingual application of amiloride (dotted lines). $\boldsymbol{F}, \mathbf{G}$, Integrated taste responses from the GSP in a Control mouse to a concentration series of $\mathrm{NaCl}_{\text {and }}$ to $0.5 \mathrm{M} \mathrm{NH} \mathrm{NI}_{4} \mathrm{Cl}$ before lingual application of amiloride $(\boldsymbol{F})$ and with amiloride $(\boldsymbol{G}) . \boldsymbol{H}, \boldsymbol{I}$, Integrated taste responses from the $\mathrm{GSP}$ nerve in an $\alpha \mathrm{ENaC} \mathrm{KO}$ mouse to a concentration series of NaCl and to $0.5 \mathrm{M} \mathrm{NH}{ }_{4} \mathrm{Cl}$ before lingual application of amiloride $(\boldsymbol{H})$ and with amiloride $(\boldsymbol{I})$. The record in $\boldsymbol{I}$ is broken to enable registration of responses with $\boldsymbol{G}$. Only spontaneous activity was not shown in $\boldsymbol{I}$.J, Relative taste responses to a concentration of $\mathrm{NaCl}$ from the GSP in the same control mouse in which $\boldsymbol{F}$ and $\boldsymbol{G}$ were recorded and in the same $\alpha \mathrm{ENaC} \mathrm{KO}$ mouse in which $\boldsymbol{H}$ and $\boldsymbol{I}$ were recorded before (solid lines) and with lingual application of amiloride (dotted lines). ${ }^{*} p<0.05$ in the group-related comparisons in $\boldsymbol{E}$.
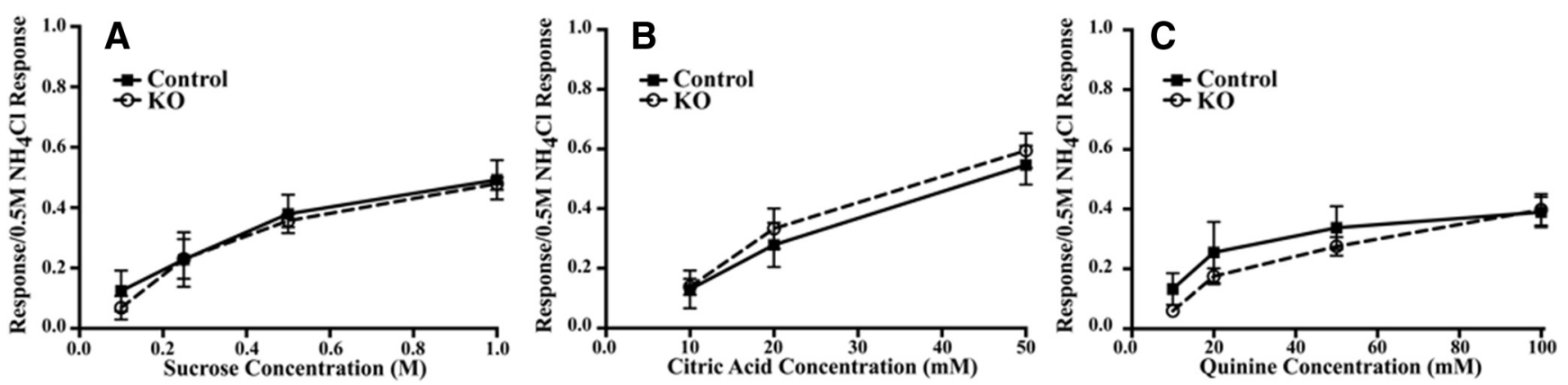

Figure 2. $\quad \boldsymbol{A}-\boldsymbol{C}$, Mean ( \pm SEM) relative taste responses to a concentration of sucrose $(\boldsymbol{A})$, citric acid $(\boldsymbol{B})$, and quinine $(\boldsymbol{C})$ from the $\mathrm{CT}$ nerve in control (Control; solid lines) and $\alpha \mathrm{ENaC}$ knock-out (KO; dotted lines) mice.

control mouse responded to $\mathrm{NaCl}$ in a manner similar to that in the rat-relative response magnitudes increased with increasing $\mathrm{NaCl}$ concentration, such that the response magnitude to $0.5 \mathrm{M} \mathrm{NaCl}$ and $0.5 \mathrm{M} \mathrm{NH}_{4} \mathrm{Cl}$ were similar and the responses were highly amiloride sensitive (Fig. $1 F, G, J$ ). By contrast, the relative $\mathrm{NaCl}$ taste responses in the GSP of an $\alpha \mathrm{ENaC}$ knock-out mouse were much smaller than those in controls for all concentrations and, like the CT nerve in these mice, the responses were not significantly suppressed by amiloride (Fig. $1 H-J$ ). Therefore, both the CT and the GSP nerves show profound functional deficits in response to $\mathrm{NaCl}$ stimulation.
Postnatal body weights were not affected by the removal of Scnn1a

We now know that Scnnla was selectively removed from taste buds in the mouths of $\alpha \mathrm{ENaC}$ knock-out mice. However, since K19 is also expressed in the gut of mice (Brembeck et al., 2001), it is likely that Scnn1a was also removed in epithelial cells that transport $\mathrm{NaCl}$ (Duc et al., 1994; Chandrashekar et al., 2010).

To examine whether the removal of the Scnnla gene had general, somatic effects on the development of $\alpha \mathrm{ENaC}$ knock-out mice, we examined the body weights of $\alpha \mathrm{ENaC}$ knock-out and 
control mice from P5 to P30 ( $\alpha$ ENaC knock-out mice, $n=16$; control mice, $n=20$ ). We found that the mean body weights of $\alpha \mathrm{ENaC}$ knock-out mice were at least $90 \%$ those of control mice at P5, P10, P15, P20, P25, and P30, and that both groups followed the developmental body weight data shown for C57BL/6J mice from The Jackson Laboratory. Moreover, there were no apparent differences in overall appearance, or ingestive or motor abilities. Similar observations of $\alpha \mathrm{ENaC}$ knock-out mice were reported by Chandrashekar et al. (2010).

In summary, the $\alpha \mathrm{ENaC}$ knock-out mice used here are similar to those used to study peripheral taste function in mice with the same genotype as ours (Chandrashekar et al., 2010), where it was convincingly shown that sodium salt taste was selectively knocked out of the peripheral taste system, yielding a taste modality-specific loss of afferent information sent to the gustatory brainstem.

Removal of Scnn1a from taste buds throughout development leads to much larger terminal fields in the NST

Qualitative appearance of terminal fields in control and $\alpha E N a C$ knock-out mice

Figure 3 shows the terminal fields of the IX, CT, and GSP nerves, and the merged image of all terminal fields in a control and a $\alpha \mathrm{ENaC}$ knock-out mouse for the four dorsal-ventral zones within the NST that were described in Materials and Methods. For all fields in all zones, the densest portion of the terminal field was located in the rostral and medial portion of the NST. This is similar to that reported in rat (King and Hill, 1991; May and Hill, 2006) and in mouse (C57BL/6 × C3H background; Sun et al., 2015). For both groups, the terminal fields extended more caudally in the dorsal and intermediate zones compared with the far dorsal and ventral zones (Fig. 3). Moreover, the IX nerve terminal field seemed to occupy more of the NST and with a higher density in the far dorsal, dorsal, and intermediate zones than in the ventral zone. By contrast, the CT and GSP nerve terminal fields were located more ventrally than that of the IX for both groups (Fig. 3). Figure 3 also illustrates that more labeling for all terminal fields occurred in $\alpha \mathrm{ENaC}$ knock-out mice compared with controls, especially in the dorsal and intermediate zones (Fig. 3). As a consequence of what appears to be more labeling in $\alpha \mathrm{ENaC}$ knock-out mice, there also seems to be more overlap among all three nerve terminal fields (Fig. $3 D, H, L, P, T, X, B B, F F$ ). The following sections describe the quantification data supporting these observations.

Measurements of terminal field volumes

Control mice. In control mice, the mean ( \pm SEM) number of 50 $\mu \mathrm{m}$ sections containing any terminal field label was $10.0 \pm 0.4$ sections, and the total terminal field volumes for the IX, CT, and GSP nerves were similar to each other (Fig. 4). The total terminal field volume of the overlap between the CT and the GSP nerves was larger than those of the overlap of the IX and the GSP nerves and of the IX with the CT nerves, which were similar to each other (Fig. 4). This reflects the dorsal-to-ventral organization of the three fields within the NST, where the CT and GSP nerve terminal fields are shifted slightly more ventral than the IX (Figs. 3, 4). As would be expected, the triple overlap among all three nerves was the smallest of all terminal fields.

$\alpha E N a C$ knock-out mice. The pattern of innervation of nerves and overlaps described for $\alpha \mathrm{ENaC}$ knock-out mice were similar to that seen in control mice. However, the mean ( \pm SEM) number of $50 \mu \mathrm{m}$ sections with terminal field label in $\alpha \mathrm{ENaC}$ knockout mice $(11.7 \pm 0.5)$ was significantly greater $(p<0.05)$ than

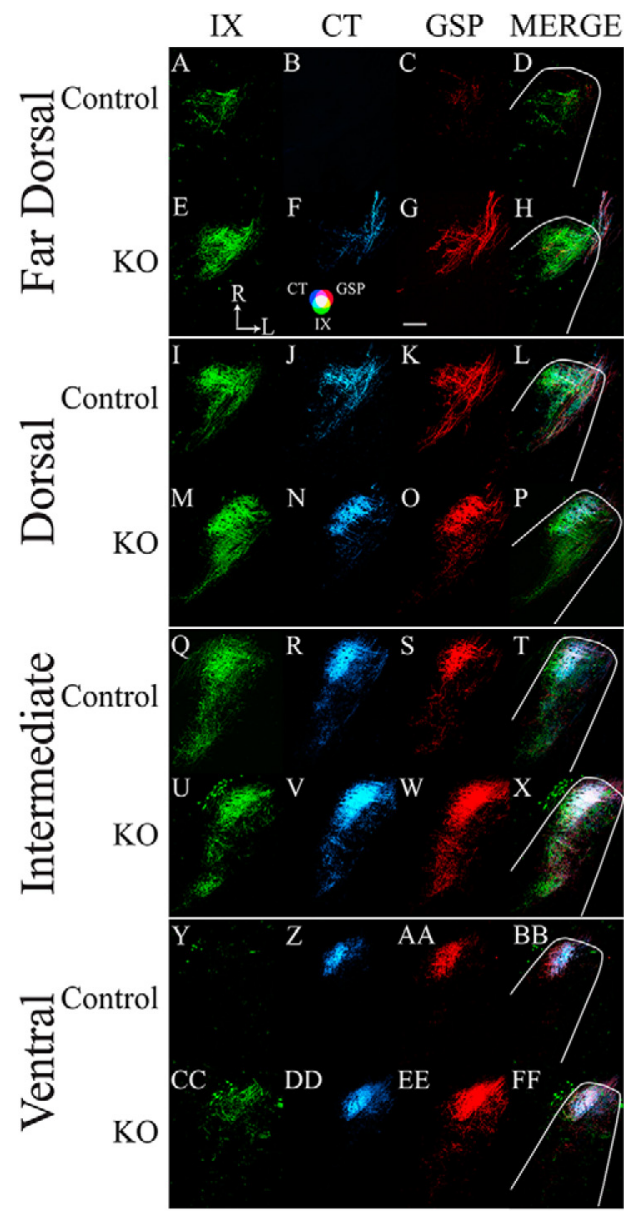

Figure 3. A-FF, Horizontal sections of labeled terminal fields of the IX nerve (green; $\boldsymbol{A}, \boldsymbol{E}, \mathbf{I}, \boldsymbol{M}, \mathbf{Q}$, $\boldsymbol{U}, \boldsymbol{Y}, \boldsymbol{C C}$, (T nerve (blue; $\boldsymbol{B}, \boldsymbol{F}, \boldsymbol{J}, \boldsymbol{N}, \boldsymbol{R}, \boldsymbol{V}, \mathbf{Z}, \mathbf{D D}$ ), and GSP nerve (red; $\boldsymbol{C}, \boldsymbol{G}, \boldsymbol{K}, \mathbf{O}, \mathbf{S}, \boldsymbol{W}, \boldsymbol{A} \boldsymbol{A}, \boldsymbol{E E}$ ), and for the merged images of all three nerves (MERGE; $D, H, L, P, T, X, B B, F F$ ) for control (Control; $A-D, I-L, Q-T$, $\boldsymbol{Y}-\boldsymbol{B B})$ and $\alpha \mathrm{ENaC}$ knock-out (KO; $\boldsymbol{E}-\boldsymbol{H}, \boldsymbol{M}-\boldsymbol{P}, \boldsymbol{U}-\boldsymbol{X}, \boldsymbol{C C}-\boldsymbol{F F})$ mice in the far dorsal $(\boldsymbol{A}-\boldsymbol{H})$, dorsa $(\boldsymbol{I}-\boldsymbol{P})$, and intermediate $(\boldsymbol{Q}-\boldsymbol{X})$ zones, and ventral $(\boldsymbol{Y}-\boldsymbol{F F})$ zones within the mouse NST. The approximate location of the NST is outlined in white, as shown in the merged images. The CT-GSP overlap is shown as magenta, the IX-GSP overlap is shown as yellow, the IX-CT overlap in shown as blue-green, and the CT-GSP-IX terminal field overlap is shown as white. Refer to the color guide in $\boldsymbol{F}$. Scale bar, $G$, $200 \mu \mathrm{m}$. R, Rostral; L, lateral (shown in E).

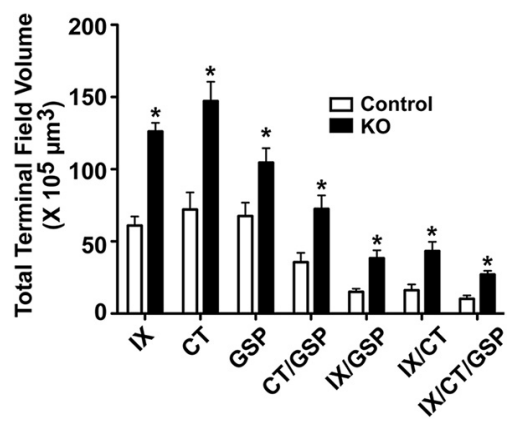

Figure 4. Mean ( \pm SEM) total terminal field volumes of the terminal field for the IX, CT, and GSP nerves and their double and triple overlap of terminal fields in control (Control, open bars) and $\alpha \mathrm{ENaC}$ knock-out (KO; solid bars) mice. ${ }^{*} p<0.05$

that in controls. Moreover, the total terminal field volumes for all nerves and all overlapping fields in $\alpha \mathrm{ENaC}$ knock-out mice were $\sim 1.6$ (GSP nerve) to 2.7 times (IX with CT overlap) greater than that of the respective total terminal field volume in controls (Fig. 4). All of the $\alpha \mathrm{ENaC}$ knock-out mice terminal field volumes 
were significantly greater than that in controls $(p<0.05)$. It is also important to see that the absolute volumes for the IX, CT, and GSP nerves were very large in $\alpha \mathrm{ENaC}$ knock-out mice compared with controls. For example, the mean CT terminal field volume in $\alpha \mathrm{ENaC}$ knock-out mice was $75 \times 10^{5} \mu \mathrm{m}^{3}$ greater than that in controls.

\section{Expansion of the terminal fields and differences in terminal field densities occur primarily in dorsal and intermediate zones}

Knowing that large group-related differences existed in total terminal field volumes, we wanted to know whether these differences were localized to specific dorsal-to-ventral zones. Moreover, we examined the regional distribution of terminal field labels through density measurements at each level to qualitatively examine the spatial organization of the labels.

\section{Far dorsal zone}

Volume

Control mice. The amount of terminal field labeling in this dorsalmost zone contained the least amount of labeling of all four zones in control mice-all seven control mice had labels in this zone. There were relatively more IX nerve labels in this zone compared with those in CT and GSP nerves (Fig. 5A). The relatively low amounts of CT and GSP nerve labels resulted in correspondingly smaller amounts of labels where the nerves overlapped with other fields (Fig. 5A).

$\alpha E N a C$ knock-out mice. As seen in control mice, all mice in this group had labels in the far dorsal zone, and the number of sections in the zone did not differ between groups $(p>0.05)$. Also, as found in control mice, there were relatively more IX labels compared with CT and GSP labels, and relatively small amounts of overlapping terminal field labels (Fig. 5A). None of the terminal field comparisons between controls and $\alpha \mathrm{ENaC}$ knock-out mice were significantly different ( $p>0.05$; Fig. $5 A$ ).

\section{Density}

The densities of labels are depicted in the heat maps shown in Figure 5, $B, D, F$, and $H$. For brevity, we show only the heat maps for the three nerves (CT, GSP, and IX) and the heat map for the triple overlap (CT with GSP with IX). The heat maps for all three nerves and the overlaps for control and $\alpha \mathrm{ENaC}$ knock-out mice were normalized to the grid box with the highest density of labels from the eight fields. For example, in the far dorsal zone, the grid box with the highest density of labels occurred for the IX nerve label in $\alpha \mathrm{ENaC}$ knock-out mice (Fig. $5 B$, white rectangle). That value (122.7; total volume of terminal field label in a grid box/ total volume for respective grid box $\times 10^{3}$ ) was used as $100 \%$ intensity, and all other density measures in this zone (volume of terminal field label/volume of the NST contained within the grid box $\times 10^{3} \mu \mathrm{m}^{3}$ ) were made relative to it (Fig. $5 B$, heat map scale).

Control mice. As would be expected from the terminal field volume results for this zone (Fig. $5 A$ ), the terminal field distribution and densities were similar among the IX, CT, and GSP nerves, with most of the labels located toward the rostral pole of the NST. However, there was a trend for a more caudal spread of CT and GSP nerve labels compared with the IX nerve (Fig. 5B).

$\alpha E N a C$ knock-out mice. The patterns of labels were similar between control and $\alpha \mathrm{ENaC}$ knock-out mice for the three nerves and for the triple overlap of these nerves. However, there were higher terminal field densities for the IX nerve than for the CT and GSP nerves in $\alpha \mathrm{ENaC}$ knock-out mice. Group-related differ- ences in terminal field densities were most notable for the IX nerve (Fig. 5B).

\section{Dorsal zone \\ Volume}

Control mice. There was more terminal field labels in this zone for the three nerves and areas of overlap compared with labels seen in the far dorsal zone (Fig. 5C). All control mice had labels in this region. The IX label continued to be the most prevalent in this zone; however, significant amounts of CT and GSP labels also occurred in the dorsal zone (Figs. 3I-L, 5C). Moreover, there were corresponding fields of overlap between two and among three nerve terminal fields (Figs. $3 L, 5 C$ ).

$\alpha E N a C$ knock-out mice. Similar to the labels seen in the far dorsal zone, there was more terminal field labels for the IX nerve than for the CT nerve followed by the GSP nerve (Figs. 3M-P, 5C) in $\alpha \mathrm{ENaC} \mathrm{knock-out} \mathrm{mice.} \mathrm{This} \mathrm{is} \mathrm{a} \mathrm{slightly} \mathrm{different} \mathrm{pattern} \mathrm{than}$ that seen in control mice. Unlike the more dorsal zone, where there were no group-related significant differences, all of the terminal field volumes were significantly greater than those seen in control mice in this zone (Fig. $5 C ; p<0.05$ ). The mean differences ranged from $71 \%$ to $350 \%$ greater for the GSP nerve and triple overlap, respectively (Fig. 5C).

\section{Density}

Control mice. The shape of the IX nerve label in control mice for the dorsal zone extended more caudally and laterally in the NST than that seen in the far dorsal zone (Fig. $5 B, D$ ) and had the greatest density of label compared with the other two nerves (Fig. $5 D)$. By contrast, the shape of the other terminal fields in controls were similar between the far dorsal and dorsal zones (Fig. $5 B, D$ ).

$\alpha E N a C$ knock-out mice. Similar to the far dorsal region, the grid box with the densest label was for the IX label (Fig. 5D, white box). However, there were also regions of high density for CT nerves in the NST of $\alpha \mathrm{ENaC}$ knock-out mice, which was also qualitatively denser and expanded more in the NST than in control mice (Fig. 5D). Similarly, the triple overlap of all three nerves in $\alpha \mathrm{ENaC}$ knock-out mice appears denser and is extended more caudally and laterally compared with control mice (Figs. $3 P, 5 D$ ).

\section{Intermediate zone}

\section{Volume}

Control mice. Unlike the two more dorsal zones in control mice, the CT and GSP nerves made extensive projections into the intermediate zone, resulting in similar terminal field volumes among the three nerves (Fig. $5 E$ ). The projection of all three nerves to the intermediate zone also contributed to substantial amounts of overlapping fields among the three nerves, most notably the relatively large amount of overlap between the CT and GSP nerves (Figs. 3T, 5E).

$\alpha E N a C$ knock-out mice. The three nerves also made extensive projections into this zone in $\alpha \mathrm{ENaC}$ knock-out mice, with similar mean terminal field volumes. As noted for the dorsal zone, all of the terminal fields in $\alpha \mathrm{ENaC}$ knock-out mice were significantly greater than those in control mice $(p<0.05$; Fig. $5 E$ ). In this zone, the mean increase in terminal field volumes ranged from a $38 \%$ increase for the GSP nerve to a $120 \%$ increase for the triple label compared with controls (Figs. $3 X, 5 E$ ).

\section{Density}

Control mice. There was nearly an identical pattern of density distribution for CT and GSP nerve labels in control mice, with the densest portions located primarily in the rostral and medial por- 
VOLUME
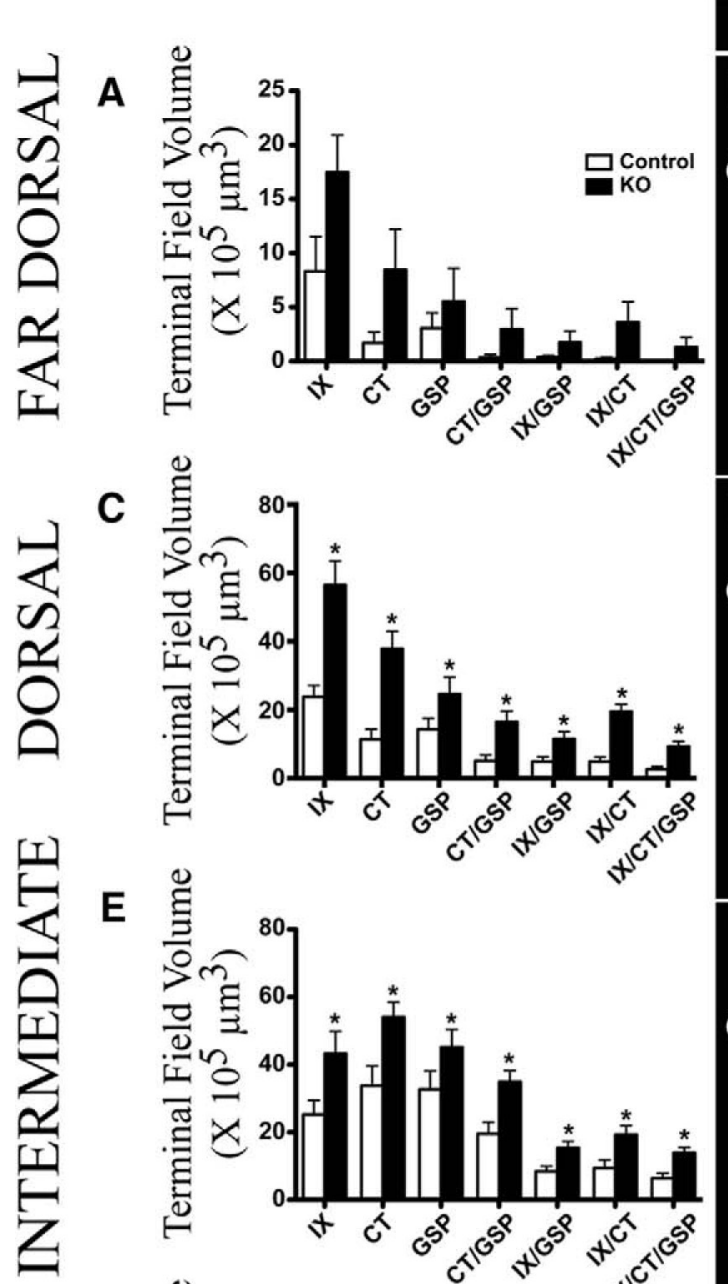

E
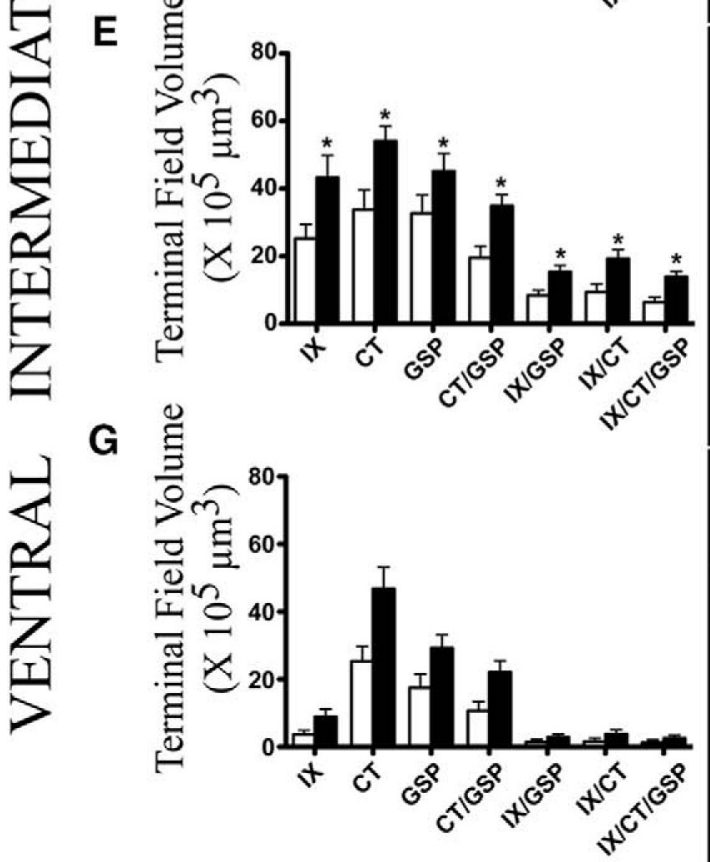

DENSITY
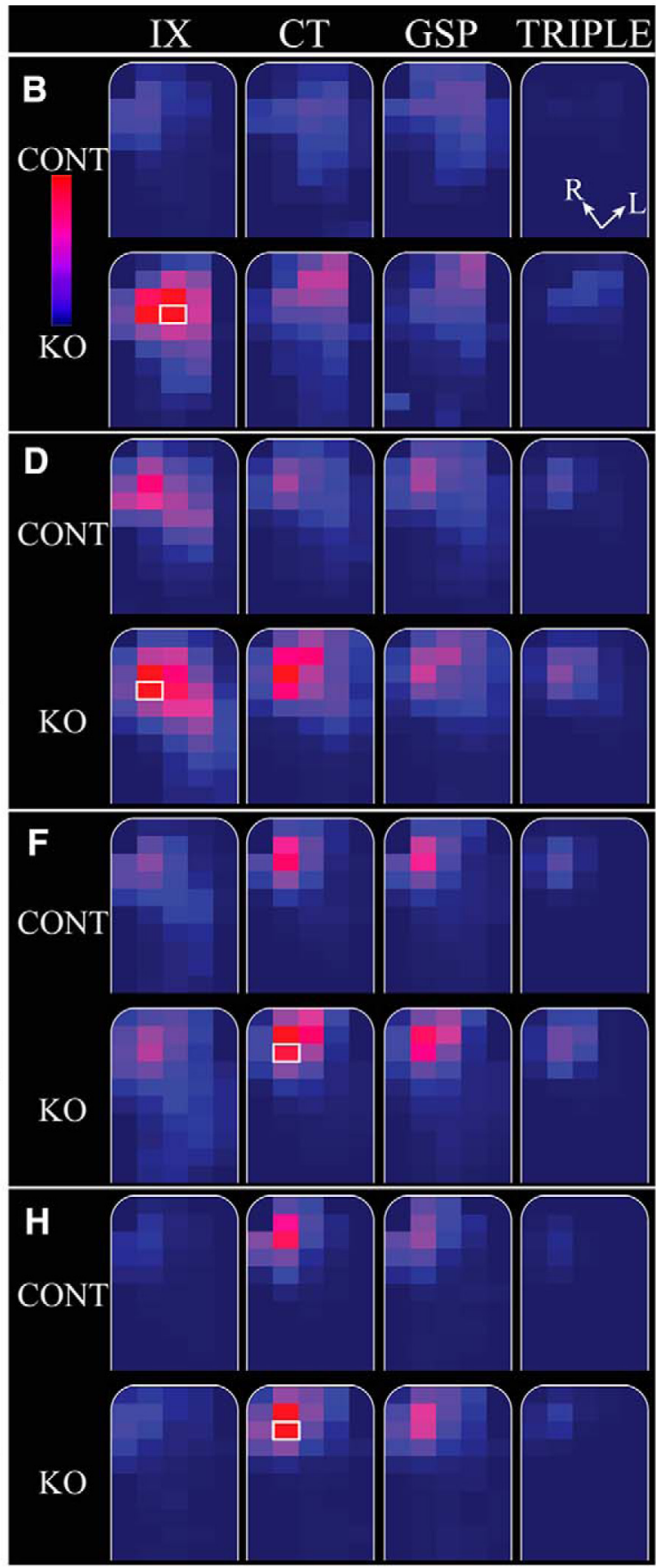

Figure 5. Mean ( \pm SEM) terminal field volumes and densities in $x-, y$-, and $z$-planes in control (Control; open bars) and $\alpha$ ENaC knock-out (KO; solid bars) mice. $A, C, E, G, M e a n( \pm S E M)$ terminal field volumes of the IX, CT, and GSP nerves and their overlapping fields for Controls (open bars) and $\alpha \mathrm{ENaC} \mathrm{KO}$ (solid bars) mice in the far dorsal $(\boldsymbol{A})$, dorsal $(\boldsymbol{C})$, intermediate $(\boldsymbol{E})$, and ventral $(\boldsymbol{G})$ zones. Note the different $y$-axis in $\boldsymbol{A}$. Asterisks shown for terminal field volumes denote $\mathrm{KO}$ means significantly greater than in Control mice $(p<0.05) . \boldsymbol{B}, \boldsymbol{D}, \boldsymbol{F}, \boldsymbol{H}$, Heat maps showing the terminal field densities (volume of terminal field label in a division/total volume of the division) for IX, CT, and GSP nerves, and for the triple overlap of all three nerve terminal fields (TRIPLE). The NST (borders shown in white) has been rotated so that the solitary tract is oriented vertically (see Materials and Methods; $\mathrm{R}$, rostral; L, lateral orientations in $\boldsymbol{B}$, TRIPLE overlap). The NST for each zone is divided into a maximum of $100 \times 100$ pixel divisions for each optical image (see Materials and Methods). The colors for the heat map of densities are on the relative scale shown in $\boldsymbol{B}$, with $0 \%$ of maximum density noted as dark blue and $100 \%$ noted as red. This relative scale was applied to each of the four zones; therefore, the maximum density was obtained from all of the divisions from Control and $\alpha \mathrm{ENaC}$ knock-out mice for the far dorsal zone, and similarly for the dorsal, intermediate, and ventral zones. The division representing $100 \%$ (brightest red) in $\boldsymbol{B}, \boldsymbol{D}, \boldsymbol{F}$, and $\boldsymbol{H}$ are shown by a white border around the respective $100 \times 100$ pixel division (e.g., contained in the IX nerve terminal field of $\alpha \mathrm{ENaC} \mathrm{knock-out} \mathrm{mice} \mathrm{in} \mathrm{the} \mathrm{far} \mathrm{dorsal} \mathrm{zone).}$

tions of the NST (Figs. 3Q-T, $5 F$ ). This is reflected in the densest regions of overlap among all three nerves (Fig. 5, TRIPLE).

$\alpha E N a C$ knock-out mice. The densest grid box in this zone was for the CT label (Fig. 5F). This is unlike the more dorsal zones, where the IX label produced the densest projection. The pattern of labeling was similar among the CT, GSP, and IX nerves (Figs. $3 T$, triple overlap, $5 F$, triple overlap). While the location of the densest portion of the label was shared with control mice (i.e., rostral and medial NST), the label in $\alpha \mathrm{ENaC}$ knock-out mice extended beyond that seen in control mice. The extension was 
primarily caudally and laterally for the IX, CT, and GSP nerves, and the triple overlap (Figs. $3 X, 5 F$ ).

\section{Ventral zone}

Volume

Control mice. The ventral zone received substantially more CT and GSP nerve labels than IX nerves labels in control mice (Figs. $3 Y-B B, 5 G$ ). This was reflected in a relatively large proportion of CT and GSP nerve label overlap, a small amount of overlap between IX and GSP and IX and CT nerves, and a small amount of overlap among all three nerves (Figs. $3 B B, 5 G$ ).

$\alpha E N a C$ knock-out mice. The pattern of terminal field volume in $\alpha \mathrm{ENaC}$ knockout mice was similar to that seen in control mice; however, the means for the CT and GSP nerves, and overlap of CT and GSP nerves were all greater than those in $\alpha \mathrm{ENaC}$ knock-out mice, but none were significantly different from those in controls (Fig. 5G; $p>0.05$ ). None of the other means were significantly different from those in control mice.

\section{Density}

Control mice. The pattern and the densities in the ventral zone were very similar for the CT and GSP nerves in control mice, with dense regions of terminal field labels in the rostralmedial portion of the NST (Figs. $3 Y-B B, 5 H$ ). The pattern of IX nerve terminal field labeling was confined more to the medial portion of the NST compared with the CT and GSP nerve labels (Fig. 5H).

$\alpha E N a C$ knock-out mice. Similar to the intermediate zone, the densest grid box for the ventral zone occurred in the CT nerve label (Fig. $5 H$, white box). As noted for the volume measurements, where the means were very similar for the CT and GSP nerves in $\alpha \mathrm{ENaC}$ knock-out mice, the density patterns were similar between these two nerves (Fig. $5 H$ ). Moreover, the density of labels for the CT and GSP nerves was more in the lateral NST regions compared with control mice.

\section{Terminal field labeling summary}

These results collectively show that there was a $60-300 \%$ greater terminal field volume in $\alpha \mathrm{ENaC}$ knock-out mice compared with controls. We show here that the terminal field volumes in $\alpha \mathrm{ENaC}$ knock-out mice are not restricted to a single field, but occur in all terminal fields. A detailed density analysis of four dorsal-ventral zones of terminal field labels revealed that the location of the densest label in the NST in each zone was similar between control and $\alpha \mathrm{ENaC}$ knock-out mice, and the basic shapes of the terminal fields were similar between groups. However, the overall number of labels in each zone and the spread of labels appear greater in $\alpha \mathrm{ENaC}$ knock-out mice compared with controls, particularly in the dorsal and intermediate zones.

Figure 6 shows a summary model of the terminal field organization of the IX, CT, and GSP nerves in the dorsal, intermediate, and ventral zones in horizontal sections for $\alpha \mathrm{ENaC}$ knock-out mice and control mice. Figure 6 depicts the relative terminal field volumes within an experimental group for each zone and the relative terminal field volume differences between groups.

Larger terminal fields in $\alpha \mathrm{ENaC}$ knock-out mice are also seen in the coronal plane

Figure 7 shows the terminal fields of the three nerves (Fig. $7 A, C, E$, control IX, CT, and GSP nerves, respectively, $B, D, F$, $\alpha \mathrm{ENaC}$ knock-out IX, CT, GSP nerves, respectively) and their triple overlap (Figure $7 G$, control, $H, \alpha \mathrm{ENaC}$ knock-out mice) in the coronal plane. The section shown in the figure is from dorsalcaudal region of the NST (Fig. $7 I, J$ ) to illustrate corresponding terminal field represented in the dorsal zone noted in Figures 3 and 5. From the labels seen in these two animals, and confirmed in two additional animals in each group, the number of CT and GSP terminal field labels in $\alpha \mathrm{ENaC}$ knock-out mice extended more medially, laterally, and ventrally than in control mice (Fig. 7). This pattern is consistent with what is shown in Figures $5 D$ and $5 F$. The pattern of innervation that we see with CT nerves in coronal sections through the NST of control mice is similar to that shown in much more detail by others (Bartel and Finger, 2013; Ganchrow et al., 2014).

\section{Ganglion cell numbers, NST volume, and NST neuron} densities are not affected by deletion of the Scnn1a gene A possible explanation for the group-related differences in terminal field size could be that more ganglion neurons survived to adulthood. That is, more ganglion cells in $\alpha \mathrm{ENaC}$ knock-out mice could translate into a larger terminal field. To test this hypothesis, we counted the cell soma of the CT and GSP nerves (geniculate ganglion) and of the IX nerve (petrosal ganglion). There were no differences in IX, CT, or GSP nerve mean numbers between $\alpha \mathrm{ENaC}$ knock-out and control mice $(p>0.05)$. The 


\section{Control}

$\mathrm{KO}$

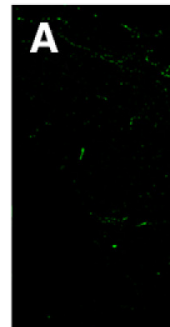

C
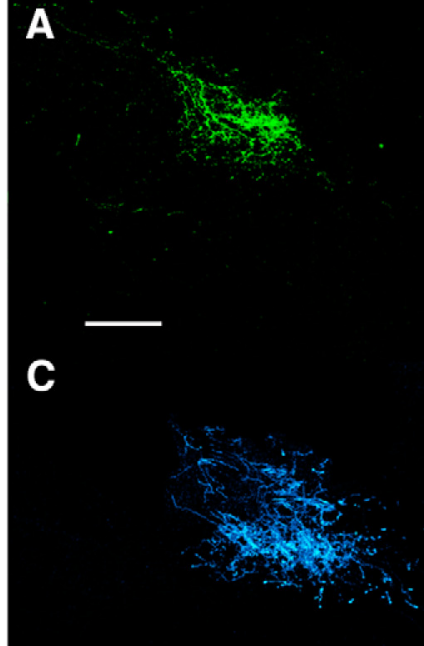

CT

\section{IX}

B

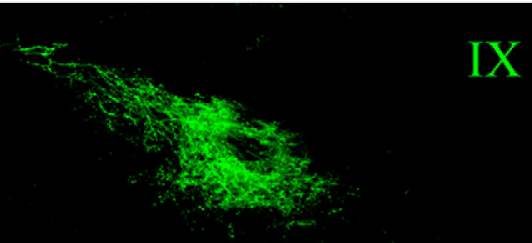

D

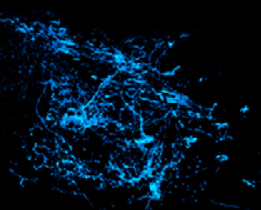

E

GSP

$\mathbf{F}$

GSP
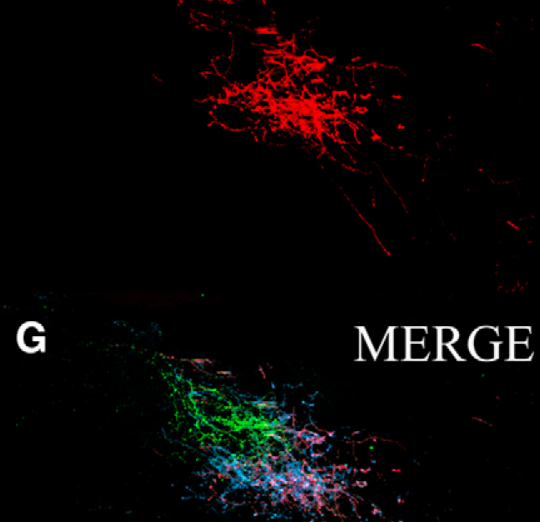

$\stackrel{\mathrm{D}}{\longrightarrow}$

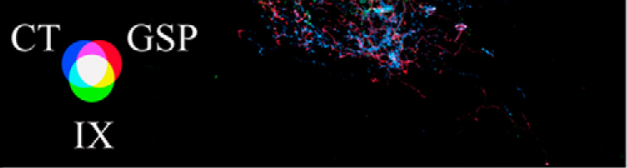

I

SolDL

J SolDL

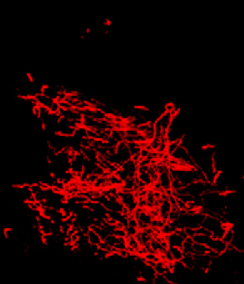

H

$\mathbf{H}$

MERGE
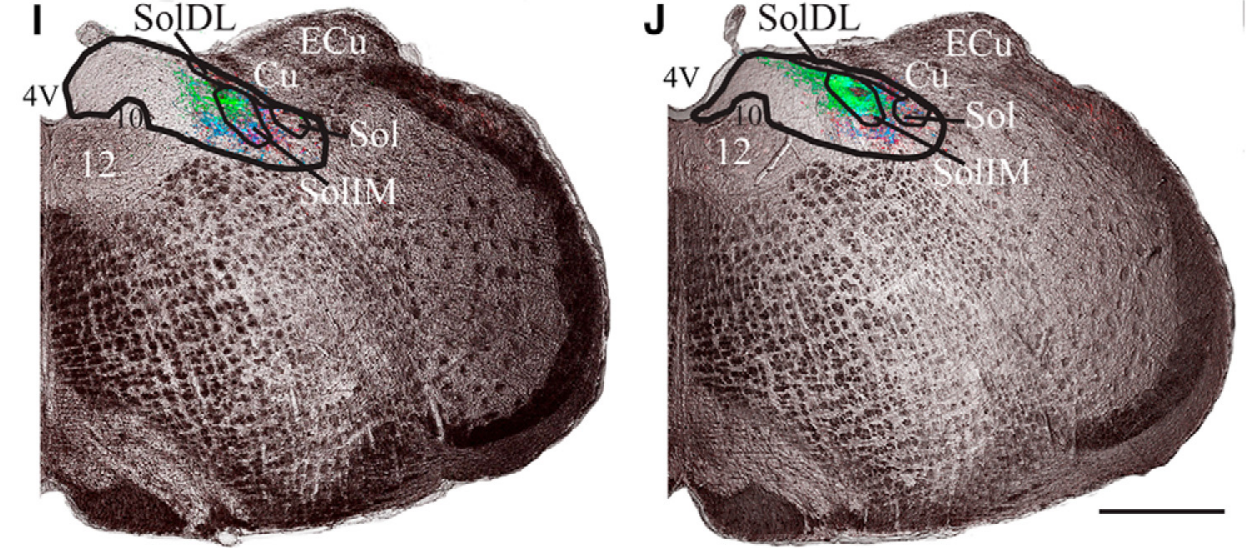

Figure 7. $A-J$, Coronal sections through the dorsal/caudal NST showing the IX nerve terminal field (green; $A, B$ ), CT nerve terminal field (blue; $C, D)$, GSP nerve terminal field (red; $\boldsymbol{E}, \boldsymbol{F}$ ), and merged $(\boldsymbol{G}, \boldsymbol{H})$ terminal fields, and the terminal fields in the right hemifield of medulla captured with transmitted light $(\boldsymbol{I}, \boldsymbol{J})$ in control (Control; $\boldsymbol{A}, \boldsymbol{C}, \boldsymbol{E}, \boldsymbol{G}, \boldsymbol{I})$ and $\alpha \mathrm{ENaC}$ knock-out $(\mathrm{KO} ; \boldsymbol{B}, \boldsymbol{D}, \boldsymbol{F}, \boldsymbol{H}$, $J)$ mice. The orientation of the sections is shown in $G$. D, Dorsal; L, lateral. The color bar for the merged images in shown in $\boldsymbol{H}$. Scale bars: $\boldsymbol{A}, 200 \mu \mathrm{m} ; \boldsymbol{J}, 500 \mu \mathrm{m}$. The black lines shown in $\boldsymbol{I}$ and $\boldsymbol{J}$ demarcate the NST (thicker lines) and structures within the NST (thinner lines). 4V, Fourth ventricle; 12, hypoglossal nuclei; 10, dorsal motor nucleus of the vagus; Cu, cuneate nucleus; ECu, external cuneate nucleus; Sol, solitary tract; SolIM, solitary tract nucleus, intermediate; SolDL, solitary tract, dorsolateral. Black, straight lines in I and $J$ point to the relevant structure in the NST. 
mean $( \pm$ SEM) ganglion cell number for the IX nerve was $320 \pm$ 11 for controls and $336 \pm 33$ for $\alpha \mathrm{ENaC}$ knock-out mice, $197 \pm$ 6 and $201 \pm 18$ for the CT nerve in controls and $\alpha \mathrm{ENaC}$ knockout mice, respectively, and $189 \pm 3$ and $203 \pm 18$ for the GSP nerve in controls and $\alpha \mathrm{ENaC}$ knock-out mice, respectively.

The large size of terminal fields in $\alpha \mathrm{ENaC}$ knock-out mice also cannot be explained by a larger target (i.e., larger NST) compared with controls or by group-related differences in NST neuron densities. Our analyses of the volume of the NST revealed that there were no group-related differences. The mean NST volume $\left( \pm\right.$ SEM) for controls was $4.81 \times 10^{8} \mu \mathrm{m}^{3}( \pm 0.2)$ and $4.53 \times 10^{8}$ $\mu \mathrm{m}^{3}( \pm 0.2)$ for $\alpha \mathrm{ENaC}$ knock-out mice $(p=0.33)$.

Finally, we found that the differences in terminal field sizes could not be explained by group-related differences in NST neuron densities in the dorsal or intermediate zones. The NST neuron density (mean \pm SEM) in the dorsal zone for controls was $13.1 \pm 0.5$ and $13.0 \pm 0.4$ neurons/100,000 $\mu \mathrm{m}^{3}$ for $\alpha \mathrm{ENaC}$ knock-out mice $(p=0.93)$. For the intermediate zone, the control mice and $\alpha \mathrm{ENaC}$ knock-out mice had respective neuron densities of $12.5 \pm 0.5$ and $12.8 \pm 0.3$ neurons $/ 100,000 \mu \mathrm{m}^{3}$ $(p=0.64)$.

\section{Discussion}

Deletion of the gene responsible for $\alpha \mathrm{ENaC}$ in mouse taste buds during embryonic development and continuing through adulthood resulted in extensive expansion of the terminal fields of three nerves that carry gustatory information from the tongue to the NST. We show here that the terminal fields in $\alpha \mathrm{ENaC}$ knockout mice expanded by as much as three times compared with controls, resulting primarily from higher densities of labels in the same terminal field areas as innervated in controls.

The gene deletion selectively disrupted sodium taste responses from the CT and GSP. Both nerves innervate taste bud cells that have $\alpha \mathrm{ENaC}$ and have been attributed to the discrimination of sodium salts from other salts and nonsalt taste stimuli (Heck et al., 1984; Hill et al., 1990; Spector et al., 1996; Sollars and Hill, 1998).

\section{Terminal field effects in $\alpha \mathrm{ENaC}$ knock-out mice are similar to those in life-long dietary sodium restriction in rats}

One of the driving forces in using mice with targeted deletion of the $\alpha \mathrm{ENaC}$ gene was the ability to examine the role of a single taste modality (i.e., sodium salt taste) on terminal field development with minimal (or the absence of) off-target effects. Our $\alpha \mathrm{ENaC}$ knock-out mice had no gross developmental deficits. This is in contrast to a rat model that we used previously, which yielded similar functional taste responses from the CT nerve and terminal field effects to what is reported here, but had severe deficits in somatic growth that suggested nutritionally related (i.e., non-activity-dependent) effects (May and Hill, 2006). Rats fed a sodium-restricted diet $(0.03 \% \mathrm{NaCl})$ from $3 \mathrm{~d}$ postconception, via their mothers, through adulthood showed selective sodium taste response deficits in the CT nerve and enlarged terminal fields of the CT and IX nerves in the NST at adulthood (Hill et al., 1986; Hill, 1987; May and Hill, 2006; Sollars et al., 2006). As found for $\alpha \mathrm{ENaC}$ knock-out mice, the sodiumrestricted rats had control-like amiloride-insensitive $\mathrm{NaCl}$ responses. The sodium-restricted rats did not have $\mathrm{NaCl}$ in the diet to drive these responses; however, they did ingest other salts, which would provide some of the amiloride-insensitive response (Formaker and Hill, 1988; Hill et al., 1990). Interestingly, there were no group-related differences in GSP terminal field size in the sodium-restricted rats (Sollars and Hill, 2000). This result can be predicted from functional data because the amiloridesensitive $\mathrm{NaCl}$ response from the GSP nerve in the experimental rats was not affected by the low-sodium diet (Sollars and Hill, 2000). Thus, there are striking similarities between these two experimental manipulations_- both groups showed that expanded terminal fields were associated with highly specific, decreased amiloride-sensitive taste responses to $\mathrm{NaCl}$ in the respective nerves (i.e., salt taste-elicited taste activity). The exception to this relationship is the IX nerve terminal field in life-long sodiumrestricted rats and in $\alpha \mathrm{ENaC}$ knock-out mice is two times that of controls. It is highly unlikely that there is a significant alteration in sodium-salt taste responses in either species because the IX nerve is relatively poorly responsive to $\mathrm{NaCl}$ and not suppressed by amiloride (Formaker and Hill, 1988; Ninomiya et al., 1991; Ninomiya, 1998). Importantly, Chandrashekar et al. (2010) also showed a lack of the appropriate subunit composition of the $\mathrm{ENaC}$ channel in posterior taste buds to transduce the amiloride component of the $\mathrm{NaCl}$ taste response in both knock-out and control mice.

\section{Enlarged terminal fields may relate to a failure to prune exuberant axonal arbors}

One of the hallmarks of circuit development in mammalian sensory systems is that central terminal fields are large during early development and exuberant arbors are then eliminated, or "pruned" during a period of postnatal circuit refinement (Katz and Shatz, 1996; Chen and Regehr, 2000; Hooks and Chen, 2006; Ziburkus and Guido, 2006). In rat and mouse gustatory systems, the terminal fields of the CT, GSP, and IX nerves are large, occupy the rostral and intermediate regions of the NST, and have overlapping territories with each other at P15 (Mangold and Hill, 2008). Terminal fields then decrease by up to threefold from P15 to P35, when they take on their adult terminal field characteristics (Mangold and Hill, 2008; Zheng et al., 2014). In both species, the dynamic phase of terminal field pruning approximately coincides in age with a threefold increase in relative taste response magnitudes of the CT nerve to $\mathrm{NaCl}$ (Hill and Almli, 1980; Yamada, 1980; Ferrell et al., 1981; Hill and Bour, 1985; Zheng et al., 2014).

We also noticed here that the terminal field in adult $\alpha \mathrm{ENaC}$ knock-out mice appears similar to that in young control micelarge terminal fields that overlap extensively with the fields of other nerves. This suggests that mechanisms involved in pruning terminal fields were not operational during the development of $\alpha \mathrm{ENaC}$ knock-out mice. Assuming a reliance of circuit refinement on the presence of neural activity, a decrease or absence of sodium salt taste responses during this critical period may be instrumental in the failure to prune exuberant arbors and synapses. We propose that salt taste stimulation supplied by salivary sodium as well as in the milk and chow provides the necessary neural activity to drive age-related pruning in controls but is lacking in knock-out mice.

The lack of sodium salt-elicited taste responses in the GSP nerve would also be expected to yield the observed large terminal fields in $\alpha \mathrm{ENaC}$ knock-out mice. However, as noted earlier, taste responses in the IX nerve should not have been altered in $\alpha \mathrm{ENaC}$ knock-out mice. Thus, the hypothesis that taste-elicited activity should drive the pruning of the terminal fields does not seem to follow for the IX nerve. Multiple factors may account for these results. One may be that the spontaneous activity (e.g., elicited through salivary sodium) of the IX nerve could be reduced in $\alpha \mathrm{ENaC}$ knock-out mice. A second possibility is that experimentally induced alterations in one or more terminal fields induce changes in other nerve terminal fields. Indeed, there is evidence 
that the three terminal fields compete with each other to ultimately shape terminal field organization in the rostral NST (Corson and Hill, 2011) and that changes in neurotrophic factors (e.g., BDNF) in the NST induced by one nerve may alter neighboring terminal fields (Sun et al., 2015). Finally, $\mathrm{NaCl}$ may be a more effective stimulus than that revealed through traditional recordings in anesthetized rodents. Indeed, different taste response profiles between awake and anesthetized preparations have been revealed in the NST (Nakamura and Norgren, 1991; Roussin et al., 2012). While we do not know the precise dynamics of this process, our findings here indicate that the large terminal field of the IX in knock-out mice may be influenced by the lack of pruning by the other two nerve terminal fields (i.e., CT and GSP). Moreover, knocking out other taste transduction receptors may be useful in identifying developmental interactions among terminal fields. Similarly, an examination of the terminal field of the superior laryngeal nerve, a branch of the vagus nerve that innervates taste buds caudal to the tongue and projects to the caudal NST, may provide further insights into the dynamics of these developing circuits.

\section{The rodent retinogeniculate visual system-a model for gustatory terminal field development}

Identifying the role of neuronal activity in shaping the development of sensory nerve terminal fields comes from work in the visual system, particularly in the dLGN. Before eye opening, retinal ganglion cell projections to the dLGN segregate into eyespecific layers through a process involving intrinsic, correlated, spontaneous activity in the two retinae (Katz and Shatz, 1996; Hooks and Chen, 2006). Synapses are then competitively eliminated from about the age of eye opening through an extended postnatal period through visually evoked responses (Sretavan and Shatz, 1984; Katz and Shatz, 1996; Chen and Regehr, 2000; Hooks and Chen, 2006; Ziburkus and Guido, 2006). Not all retinogeniculate development is due to neuronal activity because early projecting retinal ganglion cells are directed topographically to the LGN through chemical gradients (Pfeiffenberger et al., 2005). Nonetheless, it is clear that early "intrinsic" activity programs and later occurring, visually guided processes shape and maintain the terminal fields of both optic nerves.

We suggest that similar processes operate in the development of terminal fields in the rodent NST. Chemical guidance cues likely direct the "gustatory nerves" to the rostral and intermediate areas of the NST, where they overlap extensively with each other during embryonic and early postnatal development (Zhang and Ashwell, 2001). Then, with the onset and subsequent development of taste-elicited activity, the large terminal fields are pruned extensively to their mature size and location. Disruption of taste activity-dependent processes through a lack of one or more taste signals (e.g., salt taste) during development maintains terminal fields at an immature organization. Unanswered questions remain from this work concerning whether the expanded field in knock-out mice makes functional synapses, whether significant postsynaptic changes in the structure and function in the NST and in more central gustatory structures occur, and what effects the role changes in the circuitry that we describe here have on taste-elicited and ingestive behaviors.

\section{References}

Bartel DL, Finger TE (2013) Reactive microglia after taste nerve injury: comparison to nerve injury models of chronic pain. F1000Res 2:65. CrossRef Medline

Brembeck FH, Moffett J, Wang TC, Rustgi AK (2001) The keratin 19 pro- moter is potent for cell-specific targeting of genes in transgenic mice. Gastroenterology 120:1720-1728. CrossRef Medline

Chandrashekar J, Kuhn C, Oka Y, Yarmolinsky DA, Hummler E, Ryba NJ, Zuker CS (2010) The cells and peripheral representation of sodium taste in mice. Nature 464:297-301. CrossRef Medline

Chen C, Regehr WG (2000) Developmental remodeling of the retinogeniculate synapse. Neuron 28:955-966. CrossRef Medline

Corson SL, Hill DL (2011) Chorda tympani nerve terminal field maturation and maintenance is severely altered following changes to gustatory nerve input to the nucleus of the solitary tract. J Neurosci 31:7591-7603. CrossRef Medline

Davis BJ (1988) Computer-generated rotation analyses reveal a key threedimensional feature of the nucleus of the solitary tract. Brain Res Bull 20:545-548. CrossRef Medline

Denton DA (1982) The hunger for salt: an anthropological, physiological, and medical analysis. New York: Springer.

Duc C, Farman N, Canessa CM, Bonvalet JP, Rossier BC (1994) Cellspecific expression of epithelial sodium channel alpha, beta, and gamma subunits in aldosterone-responsive epithelia from the rat: localization by in situ hybridization and immunocytochemistry. J Cell Biol 127:19071921. CrossRef Medline

Erickson RP (1966) Nontraumatic headholder for rats. Physiol Behav 1: 97-98. CrossRef

Ferrell MF, Mistretta CM, Bradley RM (1981) Development of chorda tympani taste responses in rat. J Comp Neurol 198:37-44. CrossRef Medline

Formaker BK, Hill DL (1988) An analysis of residual $\mathrm{NaCl}$ taste response after amiloride. Am J Physiol 255:R1002-R1007. Medline

Ganchrow D, Ganchrow JR, Cicchini V, Bartel DL, Kaufman D, Girard D, Whitehead MC (2014) Nucleus of the solitary tract in the C57BL/6J mouse: subnuclear parcellation, chorda tympani nerve projections, and brainstem connections. J Comp Neurol 522:1565-1596. CrossRef Medline

Guillery RW (2002) On counting and counting errors. J Comp Neurol 447: 1-7. CrossRef Medline

Heck GL, Mierson S, DeSimone JA (1984) Salt taste transduction occurs through an amiloride-sensitive sodium transport pathway. Science 223: 403-405. CrossRef Medline

Hellekant G, af Segerstad CH, Roberts T, van der Wel H, Brouwer JN, Glaser D, Haynes R, Eichberg JW (1985) Effects of gymnemic acid on the chorda tympani proper nerve responses to sweet, sour, salty and bitter taste stimuli in the chimpanzee. Acta Physiol Scand 124:399-408. CrossRef Medline

Hill DL (1987) Susceptibility of the developing rat gustatory system to the physiological effects of dietary sodium deprivation. J Physiol 393:413424. CrossRef Medline

Hill DL, Almli CR (1980) Ontogeny of chorda tympani nerve responses to gustatory stimuli in the rat. Brain Res 197:27-38. CrossRef Medline

Hill DL, Bour TC (1985) Addition of functional amiloride-sensitive components to the receptor membrane: a possible mechanism for altered taste responses during development. Brain Res 352:310-313. Medline

Hill DL, Mistretta CM, Bradley RM (1986) Effects of dietary NaCl deprivation during early development on behavioral and neurophysiological taste responses. Behav Neurosci 100:390-398. CrossRef Medline

Hill DL, Formaker BK, White KS (1990) Perceptual characteristics of the amiloride-suppressed sodium chloride taste response in the rat. Behav Neurosci 104:734-741. CrossRef Medline

Holm S (1979) A simple sequentially rejective multiple test procedure. Scand J Stat 6:65-70.

Hooks BM, Chen C (2006) Distinct roles for spontaneous and visual activity in remodeling of the retinogeniculate synapse. Neuron 52:281-291. CrossRef Medline

Huang T, Krimm RF (2010) Developmental expression of Bdnf, Ntf4/5, and TrkB in the mouse peripheral taste system. Dev Dyn 239:2637-2646. CrossRef Medline

Hubel DH, Wiesel TN (1962) Receptive fields, binocular interaction and functional architecture in the cat's visual cortex. J Physiol 160:106-154. CrossRef Medline

Hummler E, Mérillat AM, Rubera I, Rossier BC, Beermann F (2002) Conditional gene targeting of the Scnnla (alphaENaC) gene locus. Genesis 32:169-172. CrossRef Medline

Katz LC, Shatz CJ (1996) Synaptic activity and the construction of cortical circuits. Science 274:1133-1138. CrossRef Medline 
King CT, Hill DL (1991) Dietary sodium chloride deprivation throughout development selectively influences the terminal field organization of gustatory afferent fibers projecting to the rat nucleus of the solitary tract. J Comp Neurol 303:159-169. CrossRef Medline

Lasiter PS, Wong DM, Kachele DL (1989) Postnatal development of the rostral solitary nucleus in rat: dendritic morphology and mitochondrial enzyme activity. Brain Res Bull 22:313-321. CrossRef Medline

Mangold JE, Hill DL (2008) Postnatal reorganization of primary afferent terminal fields in the rat gustatory brainstem is determined by prenatal dietary history. J Comp Neurol 509:594-607. CrossRef Medline

May OL, Hill DL (2006) Gustatory terminal field organization and developmental plasticity in the nucleus of the solitary tract revealed through triple-fluorescence labeling. J Comp Neurol 497:658-669. CrossRef Medline

Mistretta CM, Hill DL (2003) Development of the taste system: basic neurobiology. In: Handbook of olfaction and gustation (Doty RL, ed), pp 759-782. New York: Dekker.

Nakamura K, Norgren R (1991) Gustatory responses of neurons in the nucleus of the solitary tract of behaving rats. J Neurophysiol 66:1232-1248. Medline

Ninomiya Y (1998) Reinnervation of cross-regenerated gustatory nerve fibers into amiloride-sensitive and amiloride-insensitive taste receptor cells. Proc Natl Acad Sci U S A 95:5347-5350. CrossRef Medline

Ninomiya Y, Tanimukai T, Yoshida S, Funakoshi M (1991) Gustatory neural responses in preweanling mice. Physiol Behav 49:913-918. CrossRef Medline

Pfeiffenberger C, Cutforth T, Woods G, Yamada J, Rentería RC, Copenhagen DR, Flanagan JG, Feldheim DA (2005) Ephrin-As and neural activity are required for eye-specific patterning during retinogeniculate mapping. Nat Neurosci 8:1022-1027. CrossRef Medline

Ridler TW, Calvard S (1978) Picture thresholding using an iterative selection method. IEEE Trans Syst Man Cybern 8:630-632. CrossRef

Roussin AT, D’Agostino AE, Fooden AM, Victor JD, Di Lorenzo PM (2012) Taste coding in the nucleus of the solitary tract of the awake, freely licking rat. J Neurosci 32:10494-10506. CrossRef Medline

Schulkin J (1991) Sodium hunger: the search for a salty taste. New York: Cambridge UP.

Shingai T, Beidler LM (1985) Response characteristics of three taste nerves in mice. Brain Res 335:245-249. CrossRef Medline

Shuler MG, Krimm RF, Hill DL (2004) Neuron/target plasticity in the peripheral gustatory system. J Comp Neurol 472:183-192. CrossRef Medline

Sollars SI, Hill DL (1998) Taste responses in the greater superficial petrosal nerve: substantial sodium salt and amiloride sensitivies demonstrated in two rat strains. Behav Neurosci 112:991-1000. CrossRef Medline

Sollars SI, Hill DL (2000) Lack of functional and morphological susceptibility of the greater superficial petrosal nerve to developmental dietary sodium restriction. Chem Senses 25:719-727. CrossRef Medline

Sollars SI, Walker BR, Thaw AK, Hill DL (2006) Age-related decrease of the chorda tympani nerve terminal field in the nucleus of the solitary tract is prevented by dietary sodium restriction during development. Neuroscience 137:1229-1236. CrossRef Medline

Spector AC, Glendinning JI (2009) Linking peripheral taste processes to behavior. Curr Opin Neurobiol 19:370-377. CrossRef Medline

Spector AC, Travers SP (2005) The representation of taste quality in the mammalian nervous system. Behav Cogn Neurosci Rev 4:143-191. CrossRef Medline

Spector AC, Guagliardo NA, St John SJ (1996) Amiloride disrupts NaCl versus $\mathrm{KCl}$ discrimination performance: implications for salt taste coding in rats. J Neurosci 16:8115-8122. Medline

Sretavan D, Shatz CJ (1984) Prenatal development of individual retinogeniculate axons during the period of segregation. Nature 308:845-848. CrossRef Medline

Sun C, Dayal A, Hill DL (2015) Expanded terminal fields of gustatory nerves accompany embryonic BDNF overexpression in mouse oral epithelia. J Neurosci 35:409-421. CrossRef Medline

Suzuki N, Bekkers JM (2010) Distinctive classes of GABAergic interneurons provide layer-specific phasic inhibition in the anterior piriform cortex. Cereb Cortex 20:2971-2984. CrossRef Medline

Vogt MB, Hill DL (1993) Enduring alterations in neurophysiological taste responses after early dietary sodium deprivation. J Neurophysiol 69:832841. Medline

Whitehead MC (1988) Neuronal architecture of the nucleus of the solitary tract in the hamster. J Comp Neurol 276:547-572. CrossRef Medline

Yamada T (1980) Chorda tympani resonses to gustatory stimuli in developing rats. Jpn J Physiol 30:631-643. CrossRef Medline

Zhang LL, Ashwell KW (2001) The development of cranial nerve and visceral afferents to the nucleus of the solitary tract in the rat. Anat Embryol (Berl) 204:135-151. CrossRef Medline

Zheng S, Sun C, Hill D (2014) Postnatal reorganization of primary gustatory afferent terminal fields in the mouse brainstem is altered by prenatal dietary sodium history. Soc Neurosci Abstr 40:780.16/A63.

Ziburkus J, Guido W (2006) Loss of binocular responses and reduced retinal convergence during the period of retinogeniculate axon segregation. J Neurophysiol 96:2775-2784. CrossRef Medline 